\title{
Allele discovery of ten candidate drought-response genes in Austrian oak using a systematically informatics approach based on 454 amplicon sequencing
}

\author{
Andreas Homolka*, Thomas Eder, Dieter Kopecky, Maria Berenyi, Kornel Burg and Silvia Fluch
}

\begin{abstract}
Background: Rise of temperatures and shortening of available water as result of predicted climate change will impose significant pressure on long-lived forest tree species. Discovering allelic variation present in drought related genes of two Austrian oak species can be the key to understand mechanisms of natural selection and provide forestry with key tools to cope with future challenges.

Results: In the present study we have used Roche 454 sequencing and developed a bioinformatic pipeline to process multiplexed tagged amplicons in order to identify single nucleotide polymorphisms and allelic sequences of ten candidate genes related to drought/osmotic stress from pedunculate oak (Quercus robur) and sessile oak ( $Q$. petraea) individuals. Out of these, eight genes of 336 oak individuals growing in Austria have been detected with a total number of 158 polymorphic sites. Allele numbers ranged from ten to 52 with observed heterozygosity ranging from 0.115 to 0.640 . All loci deviated from Hardy-Weinberg equilibrium and linkage disequilibrium was found among six combinations of loci.
\end{abstract}

Conclusions: We have characterized 183 alleles of drought related genes from oak species and detected first evidences of natural selection. Beside the potential for marker development, we have created an expandable bioinformatic pipeline for the analysis of next generation sequencing data.

\section{Background}

White oaks are native to Europe, Asia, North Africa and North America, and include sessile oak, pedunculate oak, pubescent oak (Q. pubescens) and bur oak ( $Q$. macrocarpa) among their most prominent species [1]. About two percent of the Austrian forests harbour oak trees which correspond to an area of 66,000 hectare. $Q$. petraea and Q. robur are the predominant species while Q. cerris (Turkey oak) and Q. pubescens play only a minor role [2]. In Austria as well as in Europe oak species colonize huge areas with vastly differing climatic conditions.

Rise of temperatures and shortening of available water as result of predicted climate change will impose significant pressures on long-lived forest tree species like

\footnotetext{
* Correspondence: andreas.homolka@gmx.at
Health and Environment Department, AIT Austrian Institute of Technology,

* Correspondence: andreas.homolka@gmx.at
Health and Environment Department, AIT Austrian Institute of Technology, Tulln, A-3430, Austria
}

European white oak. According to the latest predictions, we expect the average global surface temperature to increase by a maximum of $6.4^{\circ} \mathrm{C}$ within the next 90 years [3] leading to a higher frequency of severe drought events. But it is well known that different species diverge in their ability to resist drought induced damages and even within a species there is tremendous variability $[4,5]$. Inter- as well as intraspecific allelic diversity is the key element of a plants potential to adapt to a changing environment and tolerance towards drought stress. There is an increased demand for molecular tools helping to describe these variations and to prepare forestry for future challenges.

Molecular markers are the first choice for plant research and breeding [6]. Using them as landmarks, genetic maps can be established and subsequently used for identification of traits controlled by different genes (quantitative trait loci). Marker assisted selection provides 
breeders with an efficient tool for identifying desired phenotypes in large populations. Beside their use in breeding, molecular markers are highly valuable for population genetics permitting evolutionary studies and population structure interference.

Single nucleotide polymorphisms (SNPs) are commonly used for functional diversity assessment. Although they are highly abundant in the human genome and every SNP locus could potentially serve as utile marker, there are still few studies dealing with a high number of SNPs in plants [7]. Latest advances in human and animal genome analysis have created several sophisticated technologies which are capable to analyze millions of SNPs in reasonable time and with low costs [6] and can be easily transferred to applications in plants. SNP discovery technologies include bioinformatic mining of expressed sequence tag (EST) databases [8], array based methods [9], comparison of whole genomes [10] and the application of next generation sequencing (NGS) for amplicon resequencing [11]. Recently developed sequencing technologies summarized as next generation sequencing have already replaced traditional methods for detecting polymorphisms in genomes [12].

Roche 454 sequencing technology [13] is based on single strand amplification with emulsion polymerase chain reaction followed by pyrosequencing. Average readlengths of around $400 \mathrm{bp}$ and high achievable coverage makes this technology well suited for discovery of SNPs and even detection of rare alleles. Short oligonucleotide barcodes can be used to tag individual sequences and enable the parallel analysis of several targets which has been successfully demonstrated in different species [1416]. Multiplexing capabilities enable large studies including several hundred individuals with a high coverage for each sample. Therefore extensive cloning procedures to identify both haplotypes of diploid individuals as used in Sanger sequencing or generation of inbred lines [17] can be avoided. Bioinformatic haplotype interference with parsimony [18] or maximum-likelihood methods [19] is no longer necessary because each haplotype will be covered by a sufficient number of reads. The present paper describes the discovery and characterization of alleles in ten drought stress related genes originating from two oak species growing in Austria based on multiplex 454 amplicon sequencing and the development of a bioinformatic analysis pipeline.

\section{Results}

\section{Processing of 454 sequencing data}

Raw data with a total number of 253,630 reads comprising $57.8 \mathrm{Mbp}$ with an average length of 227.85 bp was delivered by the sequencing company (Table 1). Average 454 quality score of the provided sequences was 22.95 (median 25.19) with a maximum of 37.93 and a minimum of 5.50 .
We removed 45,039 reads shorter than 90 bp (Figure 1) with an average length of $67.93 \mathrm{bp}$. A total number of 298 sequences longer than $420 \mathrm{bp}$ with an average length of $447.21 \mathrm{bp}$ and a maximum of $705 \mathrm{bp}$ were trimmed. Average 454 quality score after removal of long and short sequences increased to 27.78 (median 28.24). Barcode sequences were not readable in 5,108 reads which were therefore discarded. Additionally we identified 1,863 reads with corrupt internal primers which were excluded from further analysis (Figure 1). After preprocessing 201,620 reads consisting of $53 \mathrm{Mbp}$ sequence information with an average length of $230.35 \mathrm{bp}$ remained for allele detection (Table 1).

During homopolymer (HP) correction in SCARF [20] 17,287 additional reads were removed because the software was not able to align them to the Sanger reference [21]. On average 18 individuals per locus were removed from the analysis (Table 2) because of technical errors including incorrect amplification, short reads, read quality and corrupted barcodes or internal primers. A maximum number of 28 lost individuals was found in $B M Y 7$ while in PIP1E we only lost 7 individuals.

\section{Polymorphic sites and allele identification}

Within the sequences of GLP3A we detected more than 2 alleles per individual. A minimum number of one allele and a maximum number of 12 alleles per individual with an average of 2.6 were found. GLP3A was excluded from further analysis because we suspected the amplification of a gene family or pseudogenes. Including individuals with less than four reads covering $70 \%$ of the Sanger reference 65,181 reads were removed from the 201,620 reads remaining after preprocessing. Due to low coverage an average number of 18 individuals had to be excluded from further analysis with a maximum number of 99 in DHN2 and a minimum number of two found in LEA14 and PER64 (Table 2). DHN2 was not included in the further analysis because we considered the number of individuals lost due to low coverage (99) as too high. Excluding $D H N 2$, the average percentage of recovered individuals was $92.3 \%$. On average each gene fragment was covered by 46.09 reads. In total we detected 158 polymorphic sites [SNPs and Insertions/Deletions (InDels)] among the eight remaining candidate genes (Table 3) with an average of 19.75 sites per gene. The highest number was found in LEA14 and LTP (34), whereas a minimum number of seven polymorphic sites was detected in PER64. On average 6.7 polymorphic sites occur each $100 \mathrm{bp}$ with a minimum of 2.8/100 bp in ARF16 and a maximum of 13.7/ $100 \mathrm{bp}$ in $L T P$. We found an average number of 22 alleles per gene with a maximum of 52 in $B M Y 7$ and a minimum of ten in ARF16, PER64 and RD26. The total number of detected alleles was 183. Sequences of alleles as well as genotypes of the analyzed individuals can be found in 
Table 1 Comparison between raw data and preprocessed reads

\begin{tabular}{|c|c|c|c|c|c|c|}
\hline Pool & Number of reads & $\begin{array}{c}\text { Received } \\
\text { Base pairs (Mbp) }\end{array}$ & Average length & Number of reads & $\begin{array}{l}\text { Preprocessed } \\
\text { Base pairs (Mbp) }\end{array}$ & Average length \\
\hline Oak 1 & 30,207 & 5.72 & 189.45 & 22,826 & 5.11 & 200.96 \\
\hline Oak 2 & 38,797 & 8.55 & 220.43 & 29,290 & 7.71 & 239.25 \\
\hline Oak 3 & 31,731 & 6.70 & 211.29 & 24,336 & 6.08 & 229.92 \\
\hline Oak 4 & 31,874 & 7.63 & 239.31 & 26,063 & 7.10 & 248.58 \\
\hline Oak 5 & 33,645 & 8.68 & 258.07 & 30,619 & 8.38 & 180.76 \\
\hline Oak 6 & 30,008 & 6.95 & 231.72 & 23,650 & 6.39 & 246.25 \\
\hline Oak 7 & 29,307 & 7.07 & 241.34 & 23,909 & 6.61 & 252.14 \\
\hline Oak 8 & 28,061 & 6.49 & 231.16 & 20,927 & 5.61 & 244.92 \\
\hline Total & 253,630 & 57.80 & 227.85 & 201,620 & 52.98 & 230.35 \\
\hline
\end{tabular}

Additional file 1. Each allele of an individual was covered by an average of 32.64 reads (median 28, Figure 2). Total number of effective alleles was 23.561 with a minimum of 1.253 (RD26), a maximum of 6.656 (BMY7) and a mean value of 2.945 (Table 3 ). Values for expected heterozygosity ranged from 0.202 (RD26) to 0.851 (BMY7) with an average number of 0.545 . Regarding observed heterozygosity, a minimum of 0.115 in RD26 and a maximum of 0.640 in LEA14 was detected. The mean value of observed heterozygosity was found to be 0.347 . In all genes expected heterozygosity exceeded the observed. All loci showed significant departure from Hardy-Weinberg expectations (HWE, Guo and Thompson's exact test $[\mathrm{P}<0.05]$ ). Null alleles were present in a high frequency (above $5 \%$ ) in all loci observed. Tests for linkage disequilibrium (LD) revealed significant disequilibrium $(\mathrm{P}<0.01)$ within six pairwise combinations of loci (Additional file 2: Table S2).

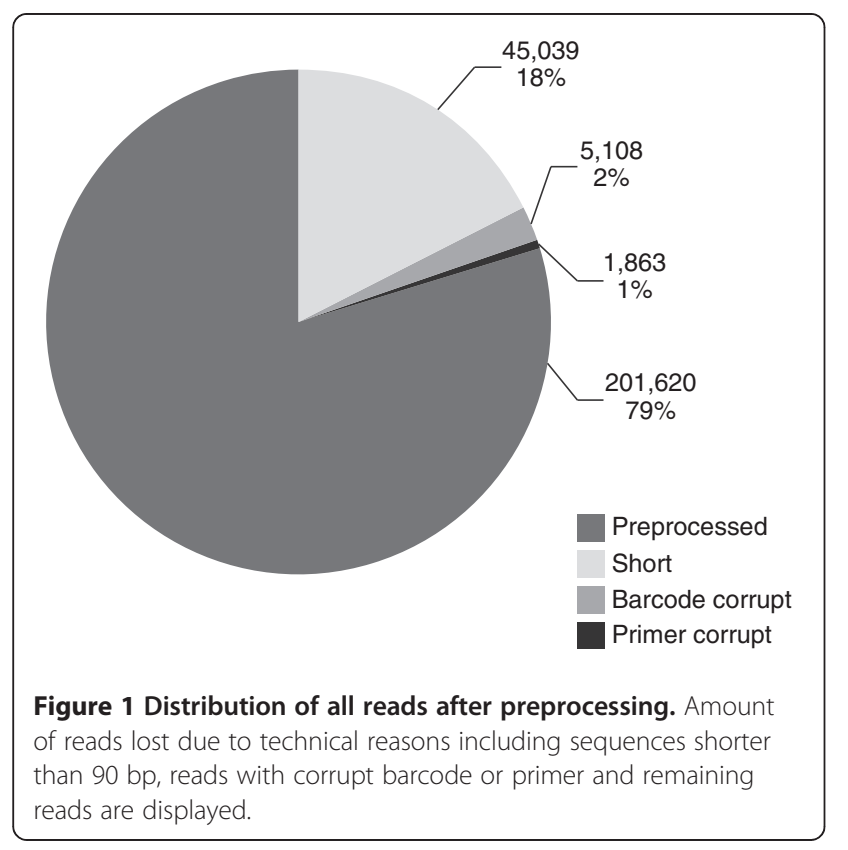

\section{Discussion}

Several studies describe the in silico detection of SNPs from the growing amount of EST data available [22,23]. However this approach is likely to be biased by the small number of individuals coming from a limited amount of populations [24]. To overcome this limitation we made use of high throughput sequencing techniques and a bioinformatic pipeline. 454 Sequencing technology developed by Roche has been chosen to analyze coding regions of drought responsive candidate genes. The main of advantage of this technique is the high number of reads generated leading to adequate coverage of each allele. Major drawbacks include the preferential amplification of short sequences and the high abundance of reading errors after homopolymer stretches. To cope with these problems we have developed a highly customizable pipeline which integrates preprocessing, statistics and error correction for 454 amplicon sequencing data and can be used to resolve multiplexed samples and to detect variants in a large number of sequences.

Different studies based on molecular markers have been conducted in oak. But the majority was investigating the

Table 2 Recovery statistics and individual coverage

\begin{tabular}{lcccccc}
\hline Gene & $\begin{array}{c}\text { Technical } \\
\text { loss }\end{array}$ & $\begin{array}{c}\text { Coverage } \\
\text { loss }\end{array}$ & \multicolumn{4}{c}{ Remaining } \\
Individuals & Reads & $\begin{array}{c}\text { Average } \\
\text { coverage }\end{array}$ \\
\hline ARF16 & 27 & 18 & 291 & $(86.6 \%)$ & 9,327 & 32.05 \\
BMY7 & 28 & 16 & 292 & $(86.9 \%)$ & 13,189 & 45.17 \\
DHN2 & 22 & 99 & n.a. & & n.a. & n.a. \\
ERD8 & 8 & 9 & 319 & $(94.9 \%)$ & 11,941 & 37.43 \\
LEA14 & 25 & 2 & 309 & $(92.0 \%)$ & 16,102 & 52.11 \\
LTP & 18 & 5 & 313 & $(93.2 \%)$ & 20,409 & 65.20 \\
PER64 & 11 & 2 & 323 & $(96.1 \%)$ & 22,628 & 70.06 \\
PIP1E & 7 & 4 & 325 & $(96.7 \%)$ & 11,364 & 34.97 \\
RD26 & 15 & 9 & 312 & $(92.9 \%)$ & 9,898 & 31.72 \\
Average & 18 & 18 & 310 & $(92.3 \%)$ & 14,357 & 46.09 \\
Total & 161 & 164 & 2,484 & & 114,858 & \\
\hline
\end{tabular}


Table 3 Polymorphisms detected

\begin{tabular}{lcccccccc}
\hline Gene & $\mathbf{S}$ & $\mathbf{N}_{\mathbf{a}}$ & $\mathbf{N}_{\mathbf{e}}$ & $\mathbf{H}_{\mathbf{o}}$ & $\mathbf{H}_{\mathbf{e}}$ & $\mathbf{F}_{\mathbf{n}}$ & HWE & Mutations/100 bp \\
\hline ARF16 & 10 & 10 & 1.667 & 0.249 & 0.404 & 0.134 & 0.000 & 2.75 \\
BMY7 & 19 & 52 & 6.656 & 0.481 & 0.851 & 0.189 & 0.030 & 5.97 \\
ERD8 & 26 & 27 & 2.602 & 0.551 & 0.619 & 0.112 & 0.000 & 7.24 \\
LEA14 & 34 & 49 & 5.079 & 0.640 & 0.803 & 0.095 & 0.000 & 12.23 \\
LTP & 34 & 13 & 2.849 & 0.260 & 0.648 & 0.228 & 0.000 & 0.000 \\
PER64 & 7 & 10 & 1.817 & 0.209 & 0.444 & 0.182 & 0.000 & 3.37 \\
PIP1E & 15 & 12 & 1.638 & 0.274 & 0.391 & 0.111 & 0.000 & 0.79 \\
RD26 & 13 & 10 & 1.253 & 0.115 & 0.202 & 0.115 & 0.000 & 3.61 \\
Average & 19.75 & 22.88 & 2.945 & 0.347 & 0.545 & 0.146 & 0.004 & 6.71 \\
Total & 158 & 183 & 23.561 & & & & &
\end{tabular}

S Number of polymorphic sites, $N_{a}$ number of alleles, $N_{e}$ effective number of alleles, $H_{o}$ observed heterozygosity, $H_{e}$ expected heterozygosity, $F_{n}$ frequency of null alleles, HWE test for deviation from Hardy-Weinberg equilibrium ( $p$-value)

population history of Quercus spp. [25] and hybridisation between Q. robur and Q. petraea [26]. Only Derory et al. [27] and Quang et al. [28] used SNPs to assess allelic diversity of candidate genes. So far, this is the first study which aimed at detecting alleles of drought stress related genes of oak. With the aid of the bioinformatic pipeline presented above were able to detect a total amount of 183 alleles within eight genes of 336 oak individuals growing in Austria. The amount of alleles is comparable to results from white spruce where 173 alleles were detected in six loci from 283 individuals growing in Alaska [29]. The average number of 6.71 mutations per $100 \mathrm{bp}$ is higher or at least in the same range than in other plant species. Frequencies of 2.96 to $3.70,3.85$ or 3.83 to 7.30 have been discovered in maize [30], black poplar [31] and eucalyptus [16] which shows that the

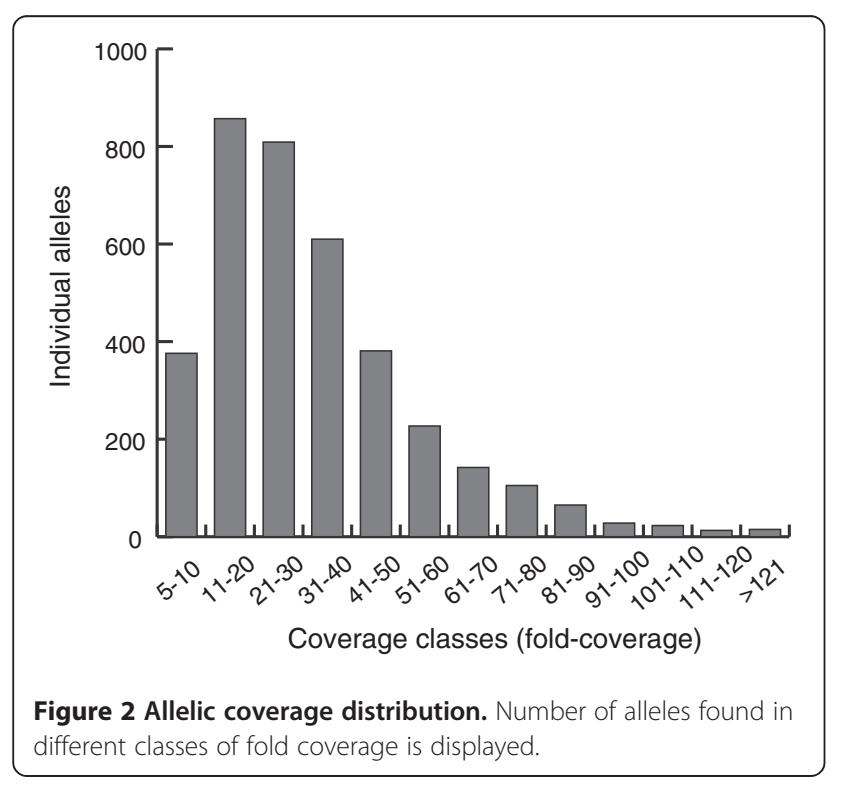

number of mutations strongly varies between species and gene analyzed. A high level of heterozygosity is present within ERD8 and LEA14 which points towards a large amount of genetic variability. Regarding the large number of individuals sampled across the heterogenic climatic area of Austria, a high variability is expected especially in genes like ERD 8 and $L E A 14$ which are directly involved in processes regulating drought response.

The high number of discovered alleles will be used as valuable source for association studies between allele frequencies and environmental variables in connection with drought stress. SNPs discovered in this study can be used to describe the genetic diversity present in two Austrian oak species and to develop molecular markers for drought tolerance if natural selection can be proven for some loci. Significant deviation from Hardy-Weinberg equilibrium as well as lower values of observed heterozygosity than expected at all loci may be the first evidence for natural selection. The deviations could partly be a result of sampling, be explained by the presence of null alleles (Table 3) or might arise from selective pressure on the coding regions. Although varying among genes, low levels of observed heterozygosity and an excess of homozygotes at $R D 26$ support the latter hypothesis as well as the presence of linkage disequilibrium between some pairs of loci. This might either occur due to epistatic natural selection where favourable combinations of genes are linked and function together as supergenes [32] or several other factors including gene flow which is well documented among several oak species [27,33,34]. Present linkage between pairs of loci is the basis of association studies which can help to identify alleles occurring more frequently in plants exposed to dry conditions. Linkage between several loci of drought reactive genes is generally expected as drought response is under control of a huge regulatory network $[35,36]$. However, this approach is limited by the fact that rapid decay of $\mathrm{LD}$ is commonly observed in forest tree 
species $[37,38]$ increasing the marker density needed for successful association studies.

Considering these findings, it points out clearly that the available dataset should be subject of further analysis like decay of LD, estimation of genetic diversity or differentiation of populations. To evaluate if selective forces were acting, different neutrality test as well as detection of outlier loci will be necessary. To evaluate if these deviations were only generated by demographic processes the results should be related to neutral markers like microsatellites found in chloroplasts (cpSSRs). If the presence of loci under selection and their association with climatic variables like temperature and precipitation could be proven, development of molecular markers will be possible. Given the predicted climate change and the resulting pressure on sessile organisms, functional markers might be a valuable tool for forestry and a basis for marker assisted selection of drought tolerant genotypes. Additional benefit arises from the fact that two different oak species were included in the analysis. Although they are mainly sympatric, Q. petraea is not as susceptible to drought induced damages as $Q$. robur. If species specific alleles can be discovered and related to environmental conditions the genetic basis of this benefit may be revealed.

\section{Conclusions}

Given next generation sequencing data of ten drought stress related genes originating from different oak species growing in Austria, we were able to discover new SNPs and characterize 183 alleles. In order to obtain these results, we have developed a semiautomatic analysis pipeline based on freely available tools and scripts. This pipeline can be fully automated and provided with a graphical user interface to make it more valuable for the scientific community. First analysis of the genetic data provides evidence of natural selection acting on the genes which makes them a target for future evolutionary studies and a potential source for molecular marker development. The alleles discovered will definitely help to understand drought adaptation processes acting in forest tree species.

\section{Availability of supporting data}

The raw data supporting the results of this article are available in the Dryad repository, http://dx.doi.org/ $10.5061 /$ dryad.83gf113b. The data sets supporting the results of this article are included within the article and its additional files.

\section{Methods}

\section{Plant material and DNA isolation}

Genomic DNA from 336 oak individuals collected across Austria $[39,40]$ was extracted with the DNeasy Plant Mini
Kit (Qiagen) according to the manufacturer's instructions. Microarray experiments with long-term drought stress applied to oak clones [21] provided the basis for selection of ten putative candidate genes for drought adaption (Table 4).

\section{Amplification of candidate genes}

Sequencing adaptors and barcodes were attached to the gene of interest following a modified two-step approach used by Schuelke [41]. In the first step, genespecific primer pairs (internal primers) with M13-tails were used to amplify regions of interest. Internal primers targeting regions with a minimum of 200 and a maximum of 375 bp were planned with Primer3 [42] using default settings. M13Fw (5'-TGTAAAACGACGGCCAGT-3') and M13Re (5' -CAGGAAACAGCTATGACC-3') were synthesized to the $5^{\prime}$-end of the internal primers. Amplicons for 454 sequencing were generated from $20 \mathrm{ng}$ of template DNA. PCR reactions were performed in $25 \mu \mathrm{l}$ total volume using $5 \mu \mathrm{l} 5 \times$ HOT FIREPol $^{\circledR}$ Blend Master Mix $12.5 \mathrm{mM} \mathrm{MgCl} 2$ without dye (Solis BioDyne) and 3 pmol of each primer. A three-step PCR program consisting of $15 \mathrm{~min}$. initial denaturation at $95^{\circ} \mathrm{C}$ followed by 32 cycles denaturation at $95^{\circ} \mathrm{C}$ for $30 \mathrm{sec}$., annealing at a temperature of $68^{\circ} \mathrm{C}$ for $45 \mathrm{sec}$., extension at $72^{\circ} \mathrm{C}$ for one minute and a final extension at $72^{\circ} \mathrm{C}$ for 8 minutes was used.

Forward primer for the second amplification consisted of the 454 sequencing adaptor A ( $5^{\prime}$-CCATCTCATCCCTGCGTGTCTCCGACTCAG-3') linked to a hexanucleotide barcode sequence corresponding to the amplified individual and the M13Fw sequence. Reverse primers consisted of the 454 sequencing adaptor B (5' - CCTATCCCCTGTGTGCCTTGGCAG TCTCAG-3') and the M13Re sequence. HOT FIREPol ${ }^{\circledR}$ Blend Master Mix and a primer concentration according to Table 5 was used for the amplification including an initial denaturation step of $95^{\circ} \mathrm{C}$ for 15 minutes. Subsequent cycling comprised denaturation at $95^{\circ} \mathrm{C}$ for $20 \mathrm{sec}$, annealing at $55^{\circ} \mathrm{C}$ for time given in Table 5 and extension at $72^{\circ} \mathrm{C}$ for 15 seconds. The number of cycles was depending on the gene region amplified and can be found in Table 5. Product size and concentration was verified with gel electrophoresis on $1.0 \%$ agarose gels.

\section{Multiplexed 454 amplicon sequencing}

PCR products of forty-two individuals per gene were pooled resulting in a total number of 80 pools. Cleaning was performed after pooling with the QIAquick PCR purification kit (QIAGEN) according to the manufacturer's instructions. Concentrations of these pools were measured on Nanodrop (Thermo Scientific) and adjusted to $30 \mathrm{ng} / \mu \mathrm{l}$ adding TE buffer $\mathrm{pH}$ 8.0. PCR products of the same individuals originating from different genes 
Table 4 Summary data of candidate genes

\begin{tabular}{|c|c|c|c|c|c|}
\hline Gene & Annotation & Accession & Primer pairs & $\mathrm{T}_{\mathrm{a}}\left({ }^{\circ} \mathrm{C}\right)$ & Length \\
\hline \multirow[t]{2}{*}{ ARF16 } & Auxin responsive factor 16 & FP033974 & Fw: 5'-M13Fw-CAGTTGATGTTGGTTGGACA-3' & 55 & 363 \\
\hline & & & Re: 5'-M13Re-ACAATAAACAAATGCTACTCA-3' & & \\
\hline \multirow[t]{2}{*}{ BMY7 } & Beta-amylase 1 & FP061723 & Fw: 5'-M13Fw-TGCATTGCCTCGTTATGATG-3' & 59 & 318 \\
\hline & & & Re: 5'-M13Re-TGAAACCATGGGTGAAACCT-3' & & \\
\hline \multirow[t]{2}{*}{ DHN2 } & Dehydrin 2 & FP045825 & Fw: 5'-M13Fw-AGCAGCAGCAAGGTC-3' & 62 & 309 \\
\hline & & & Re: 5'-M13Re-CCTTGATCTTCTCCATCACTCC-3' & & \\
\hline \multirow[t]{2}{*}{ ERD8 } & Heat shock cognate protein 80 & FP041070 & Fw: 5'-M13Fw-AGAATGACAAATCAGTGAAGGA-3' & 59 & 359 \\
\hline & & & Re: 5'-M13Re-CGCATCAAAGCAATAGCAAA-3' & & \\
\hline \multirow[t]{2}{*}{ GLP3A } & Germin-like protein 3A & FP024682 & Fw: 5'-M13Fw-GGAGACCTGGGCTTGAACTA-3' & 59 & 344 \\
\hline & & & Re: 5'-M13Re-TGTCAATGGCCTTGGAATTT-3' & & \\
\hline \multirow[t]{2}{*}{ LEA14 } & Desiccation protectant protein Lea14 & FP049285 & Fw: 5'-M13Fw-TGTGCAGATGGGGACATAGA-3' & 57 & 278 \\
\hline & & & Re: 5'-M13Re-TGCAACAAAAATTGAAGATAGGAA-3' & & \\
\hline \multirow[t]{2}{*}{ LTP } & Prolin-rich protein & FP031479 & Fw: 5'-M13Fw-GCTTCTTAGTGCTTGCCAAAA-3' & 60 & 248 \\
\hline & & & Re: 5'-M13Re-TCAGATTTCAGCCCATCTGAG-3' & & \\
\hline \multirow[t]{2}{*}{ PER64 } & Peroxidase 64 & FP051623 & Fw: 5'-M13Fw-CAACCACCACAGCATTTGAC-3' & 62 & 208 \\
\hline & & & Re: 5'-M13Re-CCTAATCTCTTGCCCACCAG-3' & & \\
\hline \multirow[t]{2}{*}{ PIP1E } & Aquaporin PIP1-2 & FP040796 & Fw: 5'-M13Fw-CTGTGGTAAAGGGCTTCCAA-3' & 58 & 313 \\
\hline & & & Re: 5'-M13Re-ACACTGCAAACCCAATAGGC-3' & & \\
\hline \multirow[t]{2}{*}{ RD26 } & Responsive to desiccation 26 & FN712698 & FW: 5'-M13Fw-AATTATTGGTGACATTGATTTG-3' & 54 & 360 \\
\hline & & & Re: 5'-M13Re-GGGGCTITTCCAATATAGAAT-3' & & \\
\hline
\end{tabular}

Accession GeneBank accession number, $\mathrm{T}_{\mathrm{a}}$ annealing temperature of gene specific primers

were combined and sent for sequencing which was carried out by GATC Biotech in an 8 gasket format run on the Genome Sequencer FLX system (454 Life Sciences) with Titanium chemistry.

\section{Bioinformatic analysis pipeline}

A semiautomatic pipeline for allele identification was developed using several publicly available software tools. The general workflow is shown in Figure 3. Sequencing data delivered in sff format was extracted using sff_extract

Table 5 PCR settings

\begin{tabular}{lccc}
\hline Gene & Annealing time (sec.) & Cycles & Primer concentration (pmol) \\
\hline ARF16 & 20 & 25 & 4 \\
BMY7 & 25 & 26 & 4 \\
DHN2 & 25 & 27 & 3 \\
ERD8 & 20 & 28 & 4 \\
GLP3A & 25 & 27 & 3 \\
LEA14 & 25 & 32 & 4 \\
LTP & 25 & 26 & 3 \\
PER64 & 25 & 28 & 4 \\
PIP1E & 20 & 26 & 4 \\
RD26 & 25 & 26 & 3 \\
\hline
\end{tabular}

(http://bioinf.comav.upv.es/sff_extract/) with the clipping option set (sff_extract $-u-c$ input.sff -o output_raw). Length and quality statistics of the sequencing runs were calculated in R 2.12.1 [43], which was also used for graphical representation. All sequences shorter than 90 base pairs were removed from the analysis with custom Perl or shell scripts because these only contained $16 \mathrm{bp}$ with possible SNP information (90 bp less $30 \mathrm{bp}$ adaptor, $6 \mathrm{bp}$ barcode, 18 bp M13 and 20 bp genespecific primer). Sequences longer than 420 bp were trimmed using FASTA-Trimmer (fastx_trimmer - -420 - $i$ input.long -o output_lenclipped.fasta) which is part of the FASTX-toolkit (http://hannonlab.cshl.edu/fastx_toolkit/index.html) because a drop of quality below a threshold of 20 (454 quality score) was observed after this length. With the aid of the FASTA-Barcode Splitter which is also part of the FASTX-toolkit names of Quercus individuals were assigned to the corresponding reads with the exact match option set (cat input_lenclipped.fasta | fastx_barcode_ splitter.pl -bcfile Tags_Oak.txt -bol -exact -prefix BC_Oak_output/-suffix ".fasta"). For this, a textfile (Tags_Oak. txt) including the names of the individuals and the barcode sequences was used. Only perfect matching barcodes were considered for further analysis. After barcode identification, FASTA-Trimmer was used to remove the first six bases of each read (fastx_trimmer $-f 7$ - $i$ input.fasta -o 


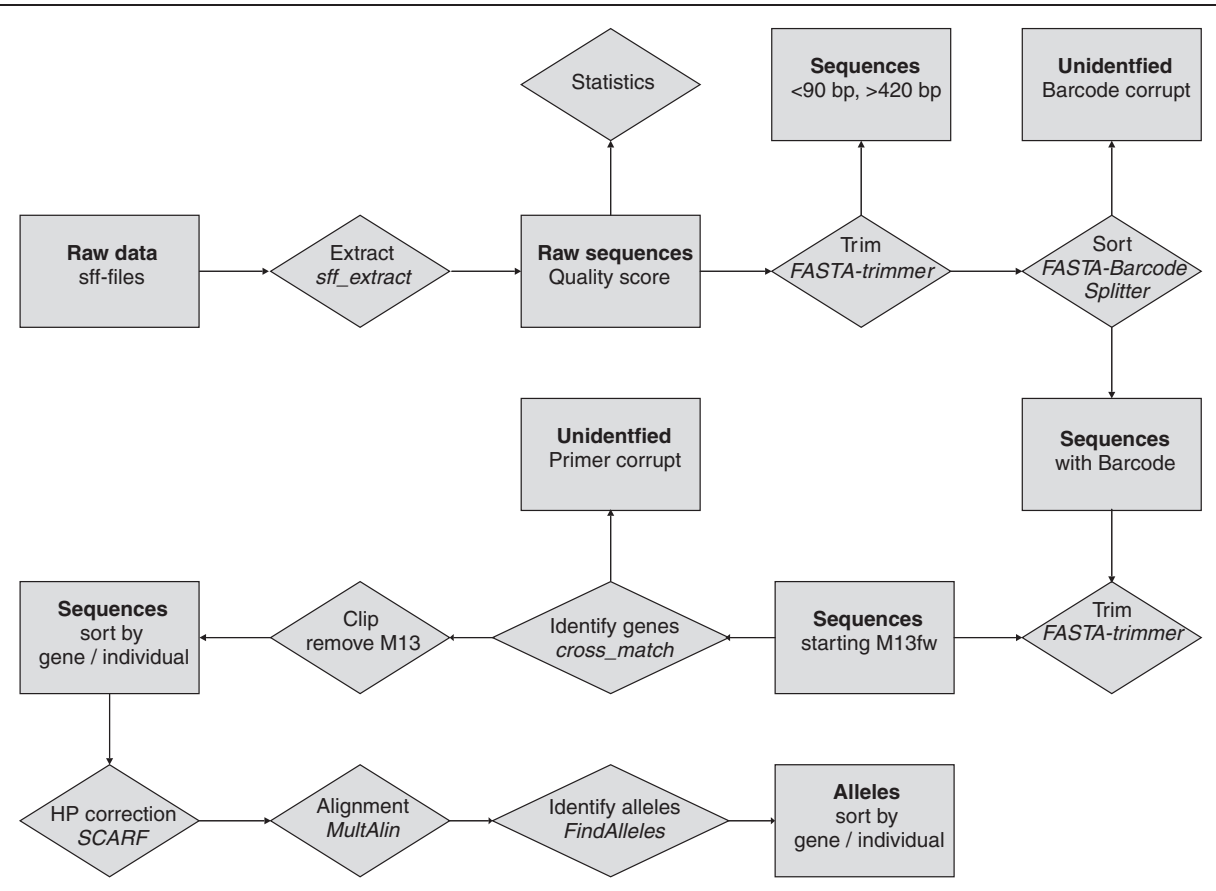

Figure 3 Flow chart of the bioinformatic pipeline developed for the analysis of a 454 amplicon resequencing experiment using freely available tools and custom Perl scripts.

output.trimmed). To identify the gene primer cross_match (http://www.phrap.org/consed/consed.html) was applied with the minimum length of matched word set to eight and the minimum alignment score set to ten (cross_match input.trimmed ../Internal_primer.fasta -minmatch 8 -minscore $10>$ output.crossmatch). Starting position of the cross_match hit was extracted from the output (egrep "^ [0-9]" input.crossmatch $\mid$ awk '\$6 $<40\{$ printf("\%s $|t \% s| t$ $1 \backslash t \% s \backslash n ", \$ 5, \$ 6, \$ 9)\}^{*}>$ output.crossmatch.filter) and used in a custom Perl script to clip M13 primers which precede the gene primer sequences.

To cope with errors resulting from the misinterpretation of homopolymer stretches by 454 sequencing we made use of the assembly tool SCARF [20]. Sanger sequences [21] of the amplicons were used as references and homopolymer correction was turned on for a minimum length of $2 \mathrm{bp}$. Therefore homopolymer errors longer than the reference sequence will be trimmed to reduce read errors. Minimum percent identity and minimum hit score were set to 80 and 100 , respectively (./scarf - $f$ input.fasta $-r$ referrence.fasta -c T - $l 2$ - $p$ - 80 -s 100). Alignment of the assembled reads was done with MultAlin [44] using the AltDNA symbol comparison table and the gap penalty at extremities parameter set to end ( $m a-c$ : altdna.tab $-x: 1$ input.clusters). Reads with gaps larger than $10 \mathrm{bp}$ were masked in the alignment using a bash script for detection and not considered for further analysis.

\section{SNP and allele detection}

We created an extensive script (FindAlleles) using BioPerl [45] which is able to identify mutations and detect alleles. Msf alignment files produced by MultAlin serve as input and are read using the Bio::AlignIO module. In a next step three different consensus sequences are calculated using the Bio::SimpleAlign module: consensus_iupac()-consensus sequence using IUPAC ambiguity codes for DNA, consensus_string()_-standard consensus sequence displaying bases which occur in plurality and consensus_string (40) - produces a standard consensus and marks positions with a lower percent-identity than $40 \%$ with "?". A column representation of all sequence reads in the alignment is created. Using the three consensus sequences created, each column is screened for possible allelic distribution or arbitrary nucleotide insertions or deletions created by 454 sequencing technology and both types are annotated with a tag. In a next step the script checks each column for an allelic distribution of a 40/60 ratio. This correction threshold value was identified by manually examining randomly chosen alignments. In the examined alignments reading errors were not present in more than ten percent of the reads. The 40/60 distribution might be created by two different nucleotides (nucleotide variation) or by the insertion or deletion of a nucleotide (InDel). If this ratio is found the position is considered as valid "allelic" distribution. If it is not found, it is considered as reading error and is automatically corrected with the nucleotide found 
in the Sanger reference if a previously set correction threshold of ten percent is reached. As SCARF only treats homopolymer errors longer than the length present in the reference, we implemented an additional routine to fill up homopolymers shorter than the reference. As we observed errors occurring already in homopolymers consisting of two nucleotides, the min homopolymer parameter which sets the amount of nucleotides in a row to trigger correction was set to one. Nucleotide positions exceeding the reference are ignored.

After the correction phase the allele identification procedure is started running again over each column. If a tag for allelic distribution is found, the process splits up the available reads into two subgroups and a recursive subroutine is started for each split alignment. Each subroutine receives the associated reads and continues with them. Reads shorter than $70 \%$ of the reference were discarded. Then the tags are checked and split up again if an allelic distribution is found. After all subroutines are finished alleles are exported to a multiple fasta file as well as statistics about the number of reads accounting for their creation and a text file with the excluded reads are generated. A cluster for allele generation was considered as valid if at least five reads covered more than 70 $\%$ of the reference sequence derived from Sanger sequencing. Number of alleles, observed and expected heterozygosities, deviation from Hardy-Weinberg equilibrium and linkage disequilibrium were calculated with Genepop 4.0 [46]. Frequency of null alleles was estimated with FreeNA [47] and effective number of alleles was calculated with GenAlEx 6 [48] using default settings.

\section{Additional files}

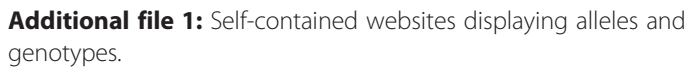

Additional file 2: Table S2. Table displaying linkage disequilibrium among pairwise combined loci.

\section{Competing interests}

The authors declare that they have no competing interests.

\section{Acknowledgements}

The project was funded by the Austrian Federal Ministry of Agriculture, Forestry, Environment and Water Management (LE 2109 GZ LE.3.2.3/0014-IV 2/2005), the Regional Office of Vienna, the Regional Office of Lower Austria (BD1 NU94-2005, LF2-FO-7059/001-05, LF4-A-25/009-2004), the Regional Office of Upper Austria, the Regional Office of Styria (A3-36E4-05/2) and the Regional Office of Burgenland. We thank Dr. Schüler and the Federal Forest Office Vienna for sharing genomic DNA with us.

\section{Authors' contributions}

$\mathrm{AH}$ participated in the design of the study, carried out the primer design and amplification of the candidate genes, analyzed bioinformatic as well as genetic data and drafted the manuscript. TE developed the allele finding algorithm. DK worked on SQL scripting and pipeline design. MB participated in primer design and candidate gene amplification. KB participated in the design of the study and commented on the manuscript. SF participated in the design of the study and commented on the manuscript. All authors read and approved the final manuscript.

Received: 26 September 2011 Accepted: 03 April 2012 Published: 03 April 2012

\section{References}

1. Liesebach M, Schüler S, Weißenbacher L, Franner T, Henninger F, Geburek T: Herkunftsversuch mit Eiche in Vorbereitung. Forstzeitung 2006, 117:40-41.

2. Dickson RE, Tomlinson PT: Oak growth, development and carbon metabolism in response to water stress. Ann Sci For 1996, 53:181-196.

3. Zhenzhu X, Guangsheng Z, Hideyuki S: Plant response to drought and rewatering. Plant Signal Behav 2010, 5:649-654.

4. Beikircher B, Mayr S: Intraspecific differences in drought tolerance and acclimation in hydraulics of Ligustrum vulgare and Viburnum lantana. Tree Physiol 2009, 29:767-775

5. LuO N, Liu J, Yu X, Jiang Y: Natural variation of drought response in Brachypodium distachyon. Physiol Plant 2011, 141:19-29.

6. Ganal MW, Altmann T, Röder MS: SNP identification in crop plants. Curr Opin Plant Biol 2009, 12:211-217.

7. Rafalski A: Applications of single nucleotide polymorphism in crop genetics. Curr Opin Plant Biol 2002, 5:94-100.

8. Le Dantec L, Chagné $D$, Pot $D$, Cantin $O$, Garnier-Géré $P$, Bedon F, Frigerio JM, Chaumeil P, Léger P, Garcia V, Laigret F, De Daruvar A, Plomion C: Automated SNP detection in expressed sequence tags: statistical considerations and application to maritime pine sequences. Plant Mol Biol 2004, 54:461-470

9. Becker A, Chao DY, Zhang X, Salt DE, Baxter I: Bulk segregant analysis using single nucleotide polymorphism microarrays. PLoS One 2011, 6: e15993.

10. Yao J, Lin H, Doddapaneni H, Civerolo EL: nWayComp: a genome-wide sequence comparison tool for multiple strains/species of phylogenetically related microorganisms. In Silico Biol 2007, 7:195-200.

11. Meyer M, Stenzel U, Myles S, Prüfer K, Hofreiter M: Targeted highthroughput sequencing of tagged nucleic acid samples. Nucleic Acids Res 2007, 35:e97.

12. Koboldt DC, Chen K, Wylie T, Larson DE, McLellan MD, Mardis ER, Weinstock GM, Wilson RK, Ding L: VarScan: variant detection in massively parallel sequencing of individual and pooled samples. Bioinformatics 2009, 25:2283-2285.

13. Margulies M, Egholm M, Altman WE, Attiya S, Bader JS, Bemben LA, Berka J, Braverman MS, Chen YJ, Chen Z, Dewell SB, Du L, Fierro JM, Gomes XV, Godwin BC, He W, Helgesen S, Ho CH, Irzyk GP, Jando SC, Alenquer ML, Jarvie TP, Jirage KB, Kim JB, Knight JR, Lanza JR, Leamon JH, Lefkowitz SM, Lei M, Li J, et al: Genome sequencing in microfabricated high-density picolitre reactors. Nature 2005, 437:376-380.

14. Stiller M, Knapp M, Stenzel U, Hofreiter M, Meyer M: Direct multiplex sequencing (DMPS)-a novel method for targeted high-throughput sequencing of ancient and highly degraded DNA. Genome Res 2009, 10:1843-1848

15. Hamady M, Walker JJ, Harris CK, Gold NJ, Knight R: Error-correcting barcoded primers for pyrosequencing hundreds of samples in multiplex. Nat Methods 2008, 5:235-237.

16. Külheim C, Yeoh SH, Maintz J, Foley WJ, Moran GF: Comparative SNP diversity among four Eucalyptus species for genes from secondary metabolite biosynthetic pathways. BMC Genomics 2009, 10:452.

17. Neigenfind J, Gyetvai G, Basekow R, Diehl S, Achenbach U, Gebhardt C, Selbig J: Haplotype inference from unphased SNP data in heterozygous polyploids based on SAT. BMC Genomics 2008, 9:356.

18. Wang IL, Chang CY: Mathematical properties and bounds on haplotyping populations by pure parsimony. Math Biosci 2011, 231:120-125.

19. Kirkpatrick BB: Haplotypes versus genotypes on pedigrees. Algorithms Mol Biol 2011, 6:10

20. Barker MS, Dlugosch KM, Reddy ACC, Amyotte SN, Rieseberg LH: SCARF: maximizing next-generation EST assemblies for evolutionary and population genomic analyses. Bioinformatics 2009, 25:535-536.

21. Spieß N, Oufir M, Matušíková I, Stierschneider M, Kopecky D, Homolka A, Burg K, Fluch S, Hausman JF, Wilhelm E: Ecophysiological and transcriptomic responses of oak (Quercus robur) to long-term drought exposure and rewatering. Environ Exp Bot 2012, 77:117-126. 
22. Neale DB, Kremer A: Forest tree genomics: growing resources and applications. Nat Rev Genet 2011, 12:111-122.

23. Lepoittevin C, Harvengt L, Plomion C, Garnier-Géré P: Association mapping for growth, straightness and wood chemistry traits in the Pinus pinaster Aquitaine breeding population. Tree Genet Genomes 2011, 8:113-126.

24. González-Martínez SC, Krutovsky KV, Neale DB: Forest-tree population genomics and adaptive evolution. New Phytol 2006, 170:227-238.

25. Petit RJ, Csaikl UM, Bordács S, Burg K, Coart E, Cottrell J, Van Dam B, Deans $J D$, Dumolin-Lapègue $S$, Fineschi $S$, et al: Chloroplast DNA variation in European white oaks. Phylogeography and patterns of diversity based on data from over 2600 populations. Forest Ecol Manag 2002, 156:5-26.

26. Scotti-Saintagne C, Mariette S, Porth I, Goicoechea PG, Barreneche T, Bodénès $C$, Burg $K$, Kremer A: Genome scanning for interspecific differentiation between two closely related oak species [Quercus robur L. and Q. petraea (Matt.) Liebl.]. Genetics 2004, 168:1615-1626.

27. Derory J, Scotti-Saintagne C, Bertocchi E, Le Dantec L, Graignic N, Jauffres A, Casasoli M, Chancerel E, Bodénès C, Alberto F, Kremer A: Contrasting relations between diversity of candidate genes and variation of bud burst in natural and segregating populations of European oaks. Heredity 2010, 105:401-411.

28. Quang ND, Ikeda S, Harada K: Nucleotide variation in Quercus crispula Blume. Heredity 2008, 101:166-174

29. Anderson LL, Hu FS, Paige KN: Phylogeographic history of white spruce during the last glacial maximum: uncovering cryptic refugia. J Hered 2011, 102:207-216

30. Ching A, Caldwell KS, Jung M, Dolan M, Smith OS, Tingey S, Morgante M Rafalski AJ: SNP frequency, haplotype structure and linkage disequilibrium in elite maize inbred lines. BMC Genet 2002, 3:19.

31. Chu Y, Su X, Huang Q, Zhang X: Patterns of DNA sequence variation at candidate gene loci in black poplar (Populus nigra L.) as revealed by single nucleotide polymorphism. Genetica 2009, 137:141-150.

32. Joron M, Frezal L, Jones RT, Chamberlain NL, Lee SF, Haag CR, Whibley A, Becuwe M, Baxter SW, Ferguson L, Wilkinson PA, Salazar C, Davidson C, Clark R, Quail MA, Beasley H, Glithero R, Lloyd C, Sims S, Jones MC, Rogers J, Jiggins CD, Ffrench-Constant RH: Chromosomal rearrangements maintain a polymorphic supergene controlling butterfly mimicry. Nature 2011 477:203-206.

33. Whittemore AT, Schaal B: Interspecific gene flow in sympatric oaks. Proc Nat Acad Sci USA 1991, 88:2540-2544.

34. Valbuena-Carabana M, González-Martínez SC, Sork VL, Collada C, Soto A, Goicoechea PG, Gil L: Gene flow and hybridization in a mixed oak forest (Quercus pyrenaica Willd. and Quercus petraea (Matts.) Liebl.) in central Spain. Heredity 2005, 95:457-465.

35. Thapa G, Dey M, Sahoo L, Panda SK: An insight into the drought stress induced alterations in plants. Biol Plantarum 2011, 55:603-613.

36. Lorenz WW, Alba R, Yu Y, Bordeaux JM, Simões M, Dean JFD: Microarray analysis and scale-free gene networks identify candidate regulators in drought-stressed roots of loblolly pine (P. taeda L.). BMC Genomics 2011, $12: 264$.

37. González-Martínez SC, Ersoz E, Brown GR, Wheeler NC, Neale DB: DNA sequence variation and selection of tag single-nucleotide polymorphisms at candidate genes for drought-stress response in Pinus taeda L. Genetics 2006, 172:1915-1926.

38. Eckert AJ, Wegrzyn JL, Pande B, Jermstad KD, Lee JM, Liechty JD, Tearse BR, Krutovsky KK, Neale DB: Multilocus patterns of nucleotide diversity and divergence reveal positive selection at candidate genes related to cold hardiness in coastal Douglas fir (Pseudotsuga menziesii var. menziesii). Genetics 2009, 183:289-298.

39. Csaikl UM, Burg K, Fineschi S, König AO, Matyas C, Petit RJ: Chloroplast DNA variation of white oaks in the alpine region. Forest Ecol Manag 2002, 156:131-1454.

40. Schüler S, Weißenbacher L: Herkunftsversuche mit Stiel- und Traubeneiche aus Österreich und angrenzenden Ländern = Provenance trials with seed sources of pendunculate and sessile oak originating from Austria and neighboring countries. BFW-Dokumentation, Wien 2010, 13:40.

41. Schuelke M: An economic method for the fluorescent labeling of PCR fragments. Nat Biotechnol 2000, 18:233-234.

42. Rozen S, Skaletsky HJ: Primer3 on the WWW for general users and for biologist programmers. In Bioinformatics Methods and Protocols: Methods in Molecular Biology. Edited by Krawetz S, Misener S. Totowa: Humana Press; 2000:365-386.
43. Ihaka R, Gentleman R: R: a language for data analysis and graphics. J Comput Graph Stat 1996, 5:399-414.

44. Corpet F: Multiple sequence alignment with hierarchical clustering. NuCl Acids Res 1988, 16:10881-10890.

45. Stajich J, Block D, Boulez K, Brenner S, Chervitz S, Dagdigian C, Fuellen G, Gilbert JG, Korf I, Lapp H, Lehväslaiho H, Matsalla C, Mungall CJ, Osborne BI, Pocock MR, Schattner P, Senger M, Stein LD, Stupka E, Wilkinson MD, Birney E: The Bioperl toolkit: perl modules for the life sciences. Genome Res 2002, 12:1611-1618.

46. Raymond M, Rousset F: GENEPOP (version 1.2): population genetics software for exact tests and ecumenicism. J Heredity 1995, 86:248-249.

47. Chapuis MP, Estoup A: Microsatellite null alleles and estimation of population differentiation. Mol Biol Evol 2007, 24:621-631.

48. Peakall R, Smouse PE: GENALEX 6: genetic analysis in Excel. Population genetic software for teaching and research. Mol Ecol Notes 2006, 6:288295.

doi:10.1186/1756-0500-5-175

Cite this article as: Homolka et al:: Allele discovery of ten candidate drought-response genes in Austrian oak using a systematically informatics approach based on 454 amplicon sequencing. BMC Research Notes 2012 5:175.

\section{Submit your next manuscript to BioMed Central and take full advantage of:}

- Convenient online submission

- Thorough peer review

- No space constraints or color figure charges

- Immediate publication on acceptance

- Inclusion in PubMed, CAS, Scopus and Google Scholar

- Research which is freely available for redistribution 